\title{
Study of the Spillover Effect on Sport to Chinese Regional Economic Development
}

\author{
Huijun Jiang ${ }^{1}$, Myeong Cheol Choi ${ }^{2} \&$ Xinke Leng ${ }^{3}$ \\ ${ }^{1}$ College of Physical Education, Hunan First Normal University, Changsha, China \\ ${ }^{2}$ Department of Global Business, Gachon University, South Korea \\ ${ }^{3}$ Physical Education Institute, Hunan University, Changsha, China \\ Correspondence: Myeong Cheol Choi, Department of Global Business, Gachon University, South Korea.
}

Received: April 30, 2019

Accepted: May 30, 2019

Online Published: June 11, 2019

doi:10.5430/ijfr.v10n5p487

URL: https://doi.org/10.5430/ijfr.v10n5p487

\begin{abstract}
Sports development can lead to the emergence of external economies, which forms part of the spillover effects on regional economic growth under certain conditions. This study uses a sample of 31 provinces in China from 20082012 to construct a panel data model to examine the role of sports development in the regional economic growth in the C-D function. The results indicate that sports development indeed brings a good incentive effect to the economy in all areas, which suggests a spillover effect of Chinese sports development that stimulates regional economic growth, but this spillover effect reflects a greater difference between different regions. Overall, Hebei, Jiangxi, Henan, Hubei, Hunan, and Sichuan have the highest coefficient of sports investment on economy, but Jilin is relatively weak.
\end{abstract}

Keywords: spillover effect, sport, economic development

\section{Introduction}

The earliest research on spillover effects began in the 1960s. MacDougall, an American economist, found that under the open conditions, there is an unusual period of growth in the host country's economy when foreign capital flows in, which suggests that foreign capital has a certain impact on the local economy. This conclusion has gradually been strengthened by theory and practice and is defined as the spillover effect ( Mustafa,Tourkia \& Ramadan 2017; Gajere, 2018).

Economists believe that this effect occurs because the capital and technology of transnational corporations have the ability to stimulate the production efficiency of enterprises, and this ability is diffused to the host country. However, the research on this spillover effect is still mainly in the field of foreign capital (e.g., Damijan; 2003; Chen 2008; Madhusudhanan 2018). In addition, Yan and Zhang (2013) also applied the spillover effect to inbound tourism and other fields, believing that the tourism consumption of foreigners has an obvious spillover effect on stimulating local economic growth (Murshed 2018; Önder 2018) .

In the sports industry, Zhang (2010); Stavrou (2018) conducted a pioneering study of the impact of foreign direct investment (FDI) on China's sports goods manufacturing industry. The results indicate that the spillover effect of FDI on the sports goods manufacturing industry is significant due to the intensification of market competition caused by the influx of foreign capital, the high density of foreign capital utilization, and the significant regional effect of FDI in this industry. It is seen that the spillover effect begins in foreign industrial enterprises, but is not limited to these.

Since the effects of labor force and capital input on the economy have been studied in detail the the purpose of this paper is to measure the impact of the development of sports on the economy. At present, the mainstream views at home and abroad maintain that the spillover effect of foreign capital mainly plays a role in the following four channels: competition, imitation and demonstration, industry connection, and personnel training and mobility channels. These channels play a significant role in the transmission of foreign capital spillovers to the host country's economy, and this difference is noteworthy in different periods and regions. The author of this paper believes that the same spillover effect also exists in the sports industry. Foreign academia has begun to pay attention to this phenomenon. 
The government's attention to sports and financial input encouragement can, to a certain extent, affect regional economic and social harmony. Hartmann and Depro (2006) introduced the concept of the spillover effect on sports development. Köln (2013) also examined the spillover effect of professional sports on demand for sports participation.

However, in recent years, the following issues have not attracted enough attention from academia: whether the impact is a positive stimulus effect or a negative or moderate one, and how strong the stimulus is. Based on this, this paper attempts to analyze the relationship between government agencies and regional economic growth by discussing the importance they attach to sports. In this way, this paper can quantitatively analyze whether sports development has a positive effect on China's regional economic development and how much this effect is.

\section{Research on the Conduction Mechanism of Sports Development Spillover Effect}

Sports development is different from foreign capital. Its effect on regional economic development is mainly produced by improving the efficiency of the main body of labor and promoting the development of related industries. The mechanism of sports stimulating a regional economic spillover effect can be considered from the following viewpoints.

\subsection{Direct Transfer Mechanism}

Economic statisticians such as Cobb and Douglas emphasize the importance of human capital in economic output. How to give full play to the role of human capital has become the focus of scholars' attention and one of the key ways for the government to improve the speed of economic growth.

In addition to genes, acquired learning is an important way to improve human capital, and so education in various countries is constantly strengthened. In addition, in recent years, sports have developed as an important channel to improve human capital. It is well recognized that participating in sports can enhance people's physique and a healthy physique is undoubtedly the guarantee of people's production and life. The government actively and comprehensively promotes sports and improves the development of sports, which can provide a good sports environment. Those who engage in sports can strengthen their physique and general well-being, thus improving their physical fitness, which may transfer to their work efficiency, thereby promoting an increase in economic output efficiency.

\subsection{Indirect Transfer Mechanism}

The development of any industry is not isolated and will inevitably affect the changes in other related industries. This can also be said of the development of the sports industry. Increasing the input of physical education can promote the development of subsidiary industries, and the indirect transmission mechanism of sports promoting economic development is realized through the transmission to other industries. Many sports clothes are dominated by sports brands, and many fans compete to buy star costumes, and many fans are keen to own the latest kit. Some sports events will also be held at special venues, which will promote the demand for construction projects.

The development of sports will certainly lead to the development of industries such as clothing, leather, timber, steel, and other metals, and will also stimulate energy consumption such as electricity, gas, and water. Frequent sports events will also continue to promote construction and a boom in sectors such as transport and retail. Sports therefore bring about an increase in employment rate and the revitalization of the economy (Rismayadi \& Maemunah 2018).

In addition, sports development can also generate additional tourism income. This is because sports delegations travel and shop at the competition venue and sports events also attract large audiences. International events such as the 2008 Beijing Olympic Games can attract large numbers of overseas tourists. According to the 2008 China Statistical Yearbook statistics, during the Beijing Olympic Games, the number of overseas tourists in Beijing reached 500,000 , around five times as many as the number of Chinese students studying abroad each year. The influx of overseas tourists will greatly stimulate consumption, promote the prosperity of the the hospitality industry, and generate significant tourism income for famous landmarks and sites.

\section{Model Construction and Index selection}

\subsection{Model Selection Description}

The study of the spillover effect of sports on regional economic growth is based on regional economic change. This paper takes the economic production function as the foundation model to conduct the analysis. A general production function that takes no account of technological progress can be represented as $Y=A f(K, L)$, following endogenous growth theory, the scale return is assumed to be constant, then it is $\lambda Y=f(\gamma K, \gamma L)$. If ordered $L=1 / \gamma$, then $Y / L=f(K / L, 1)$.Thus, the change of output per capita can be explained by per capita capital. 
If this is expanded using a linear model, if ordered $y=Y / L, k=K / L$, then the output equation can be expressed as

$$
y=A \bullet k^{\alpha}
$$

Where $Y$ is the per capita economic output, $A$ is the rate of technological progress, $k$ is per capita capital input elements, $\alpha$ is the capital factor per capita. After logarithmic change of model (1), we can obtain the following.

$$
\ln y=\ln A+\alpha \bullet \ln k
$$

In (2). $\alpha$ is the coefficient of elasticity of capital per capita. Referring to Shengyin (2013) [7], the overflow factor is added to the model. The new model is

$$
\ln y=\ln A+\alpha \bullet \ln k+\beta \bullet \ln s
$$

where $s$ is the level of sports development per capita and $\beta$ is its elastic coefficient.

Considering the vast territory of China, the factors that influence the spillover effect of sports development on the economy are the level of economic development among regions, the serious differences in the contribution rate of capital elements, the extremely uneven structure of economic development, and the uneven emphasis placed on sports. This paper will use a panel data model to describe the difference between regions (Likitrattanaporn 2018).

Because the panel model takes the time and cross-section factors of the sample into account, the empirical analysis of the case will be stricter than the separate time series and section data. Before calculating and modeling panel data, it is usually necessary to determine its specific form, whether it is a variable coefficient model, a variable intercept model, or an invariant parameter model. This needs to be determined using the characteristics of the data. The general idea is to construct two statistics, $F_{1}$ and $F_{2}$, where

$$
\begin{gathered}
F_{1}=\frac{\left(S_{2}-S_{1}\right) /[(N-1) k]}{S_{1} /(N T-N(k+1))} \bullet F[(N-1) k, N(T-k-1)] \\
F_{2}=\frac{\left(S_{3}-S_{1}\right) /[(N-1)(k+1)]}{S_{1} /(N T-N(k+1))} \bullet F[(N-1)(k+1), N(T-k-1)]
\end{gathered}
$$

where, $S_{1}, S_{2}$, and $S_{3}$ are the sum of the squared residuals of the variable coefficient, the variable intercept, and the invariant parameter models, respectively. $N T, k T$, and $k$ are the size of the section, the length of the sample, and the number of explanatory variables, respectively. According to the calculation of $F_{1}$ and $F_{2}$ in the corresponding critical value, if $F_{2}$ is less than the critical value in the statistical sense, the invariant parameter model is chosen, and if $F_{2}$ is greater than the critical value in the statistical sense and $F_{1}$ is the critical value, the variable intercept model is more suitable. If both $F_{2}$ and $F_{1}$ are larger than the statistical critical value, the variable coefficient model is optimal (Tie-Mie Gao, 2009).

After determining the specific form of the model, it is necessary to discuss its influence form, that is, the random influence model or the fixed influence model. Regarding this technical issue, Hausman argues that the stochastic impact model is a more robust model. Therefore, according to the first type of statistical hypothesis, we can focus on this type of rejection domain when we can statistically negate the original hypothesis that confirms the random effect. There may be greater assurance that the fixed impact model is more ideal. Therefore, we can use this idea for reference and analyze it using the Hausman test to make the optimal choice between the fixed influence model and the random influence model. 


\subsection{Variable Declaration}

Economic output can be measured in many ways, but at present, most of the economic output based on the production function is examined using the economic variables represented by GDP or regional GDP. This is not only because it is difficult for other indicators to measure the output of the economy in a comprehensive way, but also because the economic impact of the indicator is taken into account. GDP or regional GDP is the basic index used to reflect the total economic volume, scale, and structure of a country or region, which can reflect the overall scale of the economy.

Population as the base can reflect the level of economic development per capita, and its growth rate is the most important macroeconomic indicator to reflect economic growth. The structure of GDP can be used to examine the structure of the economy as a whole. GDP can also be used to analyze the overall price level and its changing trend, and international comparison and policy advice analysis can be conducted. This is based on the great significance of this index and the general practice of scholars at home and abroad. This paper also selects regional GDP as the explained variable. The data are from the China Statistical Yearbook. At the same time, the model also depicts the effect of per capita capital on per capita output, so the human capital selected in this paper is the population at the end of the year in each region. The data are from the China Statistical Yearbook.

Scholars have not yet reached a consensus on whether the capital factor index should be incorporated into the production function in the form of flow or stock. The selection of specific indicators is also varied. The mainstream view in China is that fixed capital stock is taken as a proxy variable, but this information has not been published by the National Bureau of Statistics of China. The calculation methods are not only complex and time-consuming, but the results also vary greatly.

On the other hand, fixed assets investment is the integration of the workload of fixed assets and related expenses of the whole society. Hao (2009) argues that it not only comprehensively reflects the scale, structure, and development speed of fixed assets investment but is also a reliable and stable data source. In view of this, this paper selects the total fixed assets investment of all regions as capital elements.

The concrete form of sports output results is sports records or number of medals, which makes it not only difficult to measure sports development results, but there is also a lack of significant difference in the statistics. Considering that sports has a certain public attribute, the selection of a sports development index to use the input rather than output, and the specific target is the regional financial expenditure on culture, sports, and media.

\section{Empirical Analysis}

\subsection{Granger Causality Test of Sports Development and Regional Economic Growth}

To verify the rationality of the model design and to explore the inherent relationship between sports development and economic growth, the Granger consistency test was carried out to determine the causal relationship between the variables. The test results are shown in Table 1.

Table 1 Results of Granger causality test between variables

\begin{tabular}{lll}
\hline Granger causality test & F statistic & P value \\
\hline S cannot Granger test cause y change & 2.98449 & 0.0536 \\
\hline y cannot Granger test cause s change & 1.80832 & 0.1675 \\
\hline k cannot Granger test cause y change & 2.81346 & 0.0632 \\
\hline y cannot Granger test cause k change & 0.72449 & 0.4863 \\
\hline
\end{tabular}

According to the test results, below significance of 0.1 , the per capita capital input and the per capita sports investment are the causes of the regional economic growth, but the reverse is not true. The driving effect of per capita capital input on economic growth is generally accepted. If the causality based on this index passes the test, it can be concluded that sports development can indeed lead to economic improvement (Ge, et.al 2018). 


\subsection{Panel Analysis}

Based on the principle of the Hausman test, the influence forms of the panel model are identified. The results show that the chi-square test statistic of the sample is 335.3314 and the corresponding $\mathrm{P}$ value is far less than 0.001 . We choose the fixed-effect influence model as the basis of this paper.

The regression residual square sum of fixed-effect variable coefficient, fixed-effect variable intercept, and mixed regression models are constructed according to the conventional method.

According to (4) and (5), $S_{1}, S_{2}$, and $S_{3}$ are $8.255134,215.6871$, and 214.7206 , respectively. We can ascertain that $F_{2}$ and $F_{1}$ are 25.9652187 and 17.2294919 and significant at the level of 0.05 . The critical two values corresponding to the statistics are $F(60,62)=1.53$ and $F(90,62)=1.48$. We can conclude that $F_{1}>F(60,62)$ and $F_{2}>F(90,62)$. Therefore, the model should choose the variable coefficient form.

Combined with the results of the Hausman test, the empirical model selected in this paper is a variable coefficient model with fixed influence.

For the fixed influence variable coefficient model, the cross-section of the model is fixed, that is, all the cross-section units at different time periods have the same interpretation of the dependent variables. The differences in the individual variables is mainly reflected in the action coefficient of different independent variables of different cross-section units. Therefore, the change in economic output in different regions mainly comes from the differences in the contribution of capital input and sports development elements in different regions. The final estimate of the model is shown as

$$
\ln \mathrm{y}_{i}=-215.068+\alpha_{i} \bullet \ln k+\beta_{i} \bullet \ln s
$$

The resolution coefficient of model (6) is as high as 0.997 , and that of the modified model is 0.994 , indicating that the fitting effect of the model is satisfactory, which is in line with the expectation. There are significant differences in the effect of capital per capita and sports development on economic growth in different regions, as shown in Table 2.

Table 2. Results of coefficient estimates for different regions

\begin{tabular}{lll}
\hline Area & $\alpha_{i}$ & $\beta_{i}$ \\
\hline Beijing & 1.753 & 0.00032 \\
\hline Tianjin & 0.998 & 0.00071 \\
\hline Hebei & 0.112 & 0.00262 \\
\hline Shanxi & 0.012 & 0.00137 \\
\hline Inner Mongolia & 0.603 & 0.00084 \\
\hline Liaoning & 0.440 & 0.00157 \\
\hline Jilin & 0.248 & 0.00005 \\
\hline Heilongjiang & 0.057 & 0.00174 \\
\hline Shanghai & 1.256 & 0.00047 \\
\hline Jiangsu & 0.897 & 0.00127 \\
\hline Zhejiang & 1.028 & 0.00089 \\
\hline Anhui & 0.270 & 0.00204 \\
\hline Fujian & 0.598 & 0.00177 \\
\hline Jiangxi & 0.260 & 0.00255 \\
\hline Shandong & 0.588 & 0.00186 \\
\hline
\end{tabular}




\begin{tabular}{lll}
\hline Henan & 0.100 & 0.00247 \\
\hline Hubei & 0.118 & 0.00246 \\
\hline Hunan & 0.077 & 0.00274 \\
\hline Guangdong & 1.164 & 0.00161 \\
\hline Guangxi & 0.329 & 0.00179 \\
\hline Hainan & 0.156 & 0.00136 \\
\hline Chongqing & 0.111 & 0.00187 \\
\hline Sichuan & 0.316 & 0.00256 \\
\hline Guizhou & 1.157 & 0.00219 \\
\hline Yunnan & 0.807 & 0.00177 \\
\hline Tibet & 0.589 & 0.00035 \\
\hline Shaanxi & 0.075 & 0.00127 \\
\hline Shaanxi & 0.075 & 0.00127 \\
\hline Gansu & 0.733 & 0.00143 \\
\hline Qinghai & 0.065 & 0.00061 \\
\hline Ningxia & 0.037 & 0.00095 \\
\hline Xinjiang & 0.059 & 0.00084
\end{tabular}

According to the estimated results of the model, the coefficients of sports elements in each region should be significantly greater than 0 , which means that sports development has a good stimulating effect on the development of the regional economy and its spillover effect is obvious. Most regions will accelerate the upgrading of the regional economy by increasing sports inputs. Overall, Hebei, Jiangxi, Henan, Hubei, Hunan, and Sichuan provinces and cities have the highest impact on the economy, indicating that these six regions attach more importance to sports (Ganyi, 2016). The spillover effect of sports development on economic growth is higher in these regions. The sports investment coefficient for Jilin is relatively low, which indicates the level of development of the sports industry in Jilin Province.

According to the statistics obtained from the China Statistical Yearbook, in 2012, Henan Province ranked first in terms of the total number of technical class athletes and second-class athletes in the country, while Hebei ranked fifth regarding the total number of technical grade athletes and third regarding second-calls athletes, indicating that Henan and Hebei are examples of national sports development. "Health affects the economy." Jiangxi attaches great importance to sports, the Jiangxi Provincial People's Government has frequently formulated policies and measures to speed up the development of sports, and the software and hardware facilities have been continuously improved. In the 10th Five-Year Plan, among the ten most influential events in Jiangxi Province, among the ten most influential initiatives, sports development holds a key position, and the promotion of Jiangxi sports to encourage economic growth has become inevitable.

At the 2008 Beijing Olympics, The Hunan delegation won five world championships, four Asian championships and 39 national championships in 2008 alone. In the 2013 National Games, Hunan athletes once again achieved remarkable results. The achievements of Hubei Province are also exciting, the government actively supervised the development of mass sports activities, the province started an upsurge in fitness.

Beijing had the highest estimate of 1.753, meaning that for every percentage point increase in fixed asset investment in Beijing, economic growth would rise by $1.753 \%$. Shanghai, Zhejiang, Guangdong, and Guizhou provinces are similar, and their estimated coefficients were higher than 1, indicating capital investment in these regions. The pull effect of investment on economic growth is also very strong. Among the aforementioned five regions, Beijing, Shanghai, Zhejiang, and Guangdong have strong economic development, and their fixed asset investment scale is among the highest in the whole country; the capital elements of these regions have played an important role in the booming economy.

On the contrary, the economic volume and development rate of Guizhou, which is a province in the west of China, lag behind those of the developed provinces, and its capital contribution is likely to be high because the region is still in the early stages of economic development. As a result, the contribution of these factors to economic growth shows a trend of increasing returns.

\subsection{Regional Comparison}


To compare the spillover effect between different regions, this paper divides 31 provinces and cities into three regions according to the traditional geographical regions: east, middle, and west. In 2001, the economic development level and structure of the three regions and the sports advancement status all have the step-by-step distribution difference (Note 1). Using three regionns as a sample to measure the strength of sports in terms of promoting economic growth can better reflect the spillover effect of plate differences.

Panel analysis is carried out with three regions to construct the panel model. Through two F statistics and Hausman test, it is found to be more reasonable for the model to select the variable coefficient form of fixed influence. The results obtained by panel regression are as follows:

$$
\ln \mathrm{y}_{i 0}=4.044+\alpha_{i 0} \bullet \ln k+\beta_{i 0} \bullet \ln s
$$

For model (7), the final coefficient and modified coefficient are 0.996 and 0.991 , respectively, and the model fit is satisfactory. The function coefficient of capital and sports development on economic growth is shown in Table 3 .

Table 3

\begin{tabular}{lll}
\hline Region & $\alpha_{i 0}$ & $\beta_{i 0}$ \\
\hline East & 1.7344 & 0.003014 \\
\hline Central & 1.2850 & 0.004929 \\
\hline West & 1.0915 & 0.001649 \\
\hline
\end{tabular}

From Table 3, we can see that the $\beta_{i 0}$ values of the three regions are all positive, which proves that the promotion of sports development has a certain positive effect on the economy. From the estimation coefficient, the spillover effect of sports on economic growth in the central region is the most powerful, and the estimated coefficient is 0.0049 , which shows that every increase of sports input in eight provinces and cities in the central region will increase economic output by $0.0049 \%$.

Relatively speaking, the western region has the weakest spillover effect. For every 1 percentage point increase in sports investment in 12 provinces and cities, the pull effect on the economy is only 0.0016 . The eastern region is in the middle of the three major regions, which is surprising but consistent with previous provincial studies.

\section{Conclusion}

The spillover effect is not solely a characteristic of foreign investment and many economic phenomena can be explained by the spillover effect, especially in the field of sports. In this study, the spillover effect is introduced into the sports industry. It is suggested that the development of the sports industry can also stimulate economic growth to a certain extent, and this incentive mechanism can be divided into two types: direct and clip incentives. Among them, the direct incentive is to improve the economic output efficiency by stimulating the working efficiency of human capital, while the indirect incentive is to promote the overall economic revitalization by driving the development of subsidiary industries.

Through the introduction of sports input elements into the classical production function and the analysis of the fixed influence variable coefficient model based on panel data, sports development is indeed found to be an important factor of economic development in China. This role mechanism has been ignored by the relevant institutions.

Empirical analysis found that Hebei, Jiangxi, Henan, Hubei, Hunan, and Sichuan provinces had the highest coefficients of the economic role of sports investment, while that of Jilin is relatively weak. Fixed asset investment in Beijing, Shanghai, Zhejiang, Guangdong, and Guizhou provinces has the greatest impact on output, which is in line with expectations. The spillover effect of regional sports promoting economic growth also verifies the rationality of this conclusion.

\section{References}

Chen, T., \& Di, R. P. (2008, December). An Empirical Study on the Phase Characteristics of Intra-Industry Spillover Effects of Fdi in China. Financial Research, 6.

Damijan, J. P. (2005). Do External Knowledge Spillovers Induce Firms' Innovations? Evidence from Slovenia. LICOS Discussion Papers. https://doi.org/10.2139/ssrn.881522 
Gajere, M. (2018). The Impact of Strategic Drift and Tactical Wear-Out: An Anecdote Example: The Case of the Distribution of Petroleum Products by Nigeria National Petroleum Corporation (NNPC). International Journal of Emerging Trends in Social Sciences, 3(2), 74-79. https://doi.org/10.20448/2001.32.74.79

Ganyi, M. F. (2016). The Liberating Potential of Oral Literature in a Globalized Context. International Journal of Publications and Social Studies, 1, 16-30. https://doi.org/10.18488/journal.135/2016.1.1/135.1.16.30

Ge, J., Wang, X., Wu, P., Huang, T., \& Jiang, H. (2018). Establishing Shipping Service Complex Standard Framework: Experience from Shanghai. International Journal of Management and Sustainability, 7(4), 215-224. https://doi.org/10.18488/journal.11.2018.74.215.224

Hao, F., Hao, H. H., \& Zhao, H. Q. (2009, April). Research on China's Benchmark Capital Stock-Based on the Revised Data of the First Economic Census. Statistics and Information Forum, 4.

Hartmann, D., \& Depro, B. (2006, April). Rethinking Sports-Based Community Crime Prevention: A Preliminary Analysis of the Relationship Between Midnight Basketball and Urban Crime Rates. Journal of Sport \& Social Issues, 2. https://doi.org/10.1177/0193723506286863

High Speed Rail Mei. (2009). Econometric Analysis method and Modeling: application and example of Eviews. Beijing: Tsinghua University Press.

Köln, S. (2013). A Quantification of the Spill-Over Effects of Professional Sports on the Demand for Sport Participation in Germany. Genehmigte Dissertation.

Likitrattanaporn, W. (2018). A Study of Language Learning Strategies for Practical Use through the Process of Cooperative Learning. International Journal of Educational Technology and Learning, 3(1), 35-44. https://doi.org/10.20448/2003.31.35.44

Madhusudhanan, S. (2018). Gender Responsive Budgeting: A Lesson Learned and Way Forward. International Journal of Applied Economics, Finance and Accounting, 2(1), 27-29. https://doi.org/10.33094/8.2017.2018.21.27.29

Murshed, M. (2018). International Tourism Demand in Bangladesh: An ARDL Bounds Test Approach. Journal of Tourism Management Research, 5(1), 50-67. https://doi.org/10.18488/journal.31.2018.51.50.67

Mustafa, H. M., Tourkia, F. B., \& Ramadan, R. M. (2017). An Overview on Evaluation of E-Learning/Training Response Time Considering Artificial Neural Networks Modeling. Journal of Education and e-Learning Research, 4(2), 46-62. https://doi.org/10.20448/journal.509.2017.42.46.62

Önder, M. (2018). Contribution of Plays and Toys to Children's Value Education. Asian Journal of Education and Training, 4(2), 146-149. https://doi.org/10.20448/journal.522.2018.42.146.149

Ouyang, S. Y. (2013, August). Quantile Regression Study on Spillover Effect of Foreign Capital. Theory and Practice of Finance and Economics, 4.

Rismayadi, B., \& Maemunah, M. (2018). Creative Economy to Increase Community Revenue Based on Tourism Object, Medalsari Village, Pangkalan District Karawang Regency. Journal of Accounting, Business and Finance Research, 3(1), 28-35. https://doi.org/10.20448/2002.31.28.35

Stavrou, P. D. (2018). Psychoanalytic Psychotherapy as a Treatment for Depression in Adolescents: A Case Study. Global Journal of Social Sciences Studies, 4(2), 91-101. https://doi.org/10.20448/807.4.2.91.101

Yan, W. B., \& Zhang, Y. (2013, April). Spillover effect of inbound Tourism on China's Regional Economic Development. China Agronomy Bulletin, 2.

Zhang, H. W. (2010, August). Analysis of Technology Spillover Effect of FDI on Chinese Sports Goods Manufacturing Industry. Sports Science, 4.

\section{Note}

Note 1. The eastern region includes Beijing, Tianjin, Hebei, Liaoning, Shanghai, Jiangsu, Zhejiang, Fujian, Shandong, Guangdong and Hainan; the central region includes Shanxi, Jilin, Heilongjiang, Anhui, Jiangxi, Henan, Hubei and Hunan; the western region includes Inner Mongolia, Guangxi, Sichuan, Chongqing, Guizhou, Yunnan, Tibet, Shaanxi, Gansu, Qinghai, Ningxia and Xinjiang. 